\title{
CARTA DE JOHN MURRA A PIERRE DUVIOLS DEL 10 DE NOVIEMBRE DE 1962 ${ }^{1}$
}

\author{
Pierre Duviols
}

Desde: Box 988, Yale Station, New Haven, Connecticut, USA:

Sr Profesor Pierre Duviols

Université d'Aix-Marseille

Señor y querido colega,

Esta semana, el correo me trajo el primer número de Etudes Latino-américaines. Leí su artículo, y el del señor Durand ${ }^{1}$ con enorme interés, y le agradezco la gentileza de haberme incluído en su lista.

Lo que Ud. dice de las fuentes utilizadas por Morúa me parece muy exacto. Creo que Polo es el autor central para cualquier estudio serio de la estructura económica y social de los incas; su importancia irá creciendo mientras nos vayamos planteando cuestiones estructurales y no solamente históricas. Me parece que Polo fue el único que hizo el esfuerzo de comprender el estado inca según su propia organización. Esto lo demostró al hallar las momias escondidas de los antiguos reyes, cosa fácil de realizar, después de entender el funcionamiento de los linajes reales incas (¿Vio Ud. la tesis de R. T. Zuidema, en Leyden? Ilegible en su forma actual, pero después de pasar tres semanas con él en el Congreso de Americanistas, en México, estoy seguro de que es muy importante. Es un análisis del sistema de zeques de Cusco).

Sin duda habrá leído Ud. el largo artículo de Rowe sobre los Incas en el Handbook of South American Indians, vol. 2, pp. 183-330, 1946. Es el mejor resumen (sin interpretación) de la civilización andina en el momento de la invasión europea. Al tratar de las fuentes, presenta a la obra de Cobo como la mejor y nos cita un ejemplo de ello, pp. 265-66. Pero esto, palabra por palabra, está copiado en Polo, Relación de los fundamentos acerca del notable daño que resulta de no guardar a los indios sus fueros edición 1916b, Urteaga, pp. 69-70.

La última vez que estuve en Europa, hablé de Polo con el historiador peruano Maticorena, en Sevilla. Tratamos de la necesidad de editar los trabajos de Polo que conocemos y de buscar otros, que quedan inéditos. Por ejemplo, sabemos que Polo fue el intendente del ejército de La Gasca, durante la guerra con Gonzalo Pizarro. Nos dice que alimenta aquel ejército con los productos almacenados en los depósitos del estado inca que seguían funcionando, aunque ya habían transcurrido 15 años desde la invasión europea. No me extrañaría mayormente encontrar algún día las listas de la intendencia, que Polo no reproduce (vea p. 77, op. cit.). Estas listas cobrarían mucha importancia para entender la economía estatal (a diferencia de la economía campesina que entendemos mejor).

Dos puntos más, sobre Morúa, que podrían interesarle:

1) según mis cotejos, una de las fuentes más copiadas por Morúa fue Repúblicas de Indias, de Jerónimo Román y Zamora [1575], 1897. Aunque Román nunca visitó la región andina, tuvo acceso a diversas fuentes de mucha importancia. Su libro salió en 1575. Compare Lib. I, ix,p. 122 de la edición de 1897 sobre los rebaños con Morúa, Lib. III, ch. xxvii, p. 335, edición Bayle; o Román II, xxvi, 68 sobre el censo, con Morúa, III, xxv, 178.

2) Si no entiendo mal, Ud. dice p. 35, en la segunda nota marcada (1), que no estamos seguros de la presencia de Polo en el Cuzco antes de 1558 cuando fue nombrado corregidor. Allí estaba ya en 1546 -ver poder para Hernando Pizarro, firmado en el Cusco ante Polo y otros testigos, p. 144, Revista del Archivo histórico del Cuzco, $\mathrm{N}^{\circ}$ 9, 1958. En diciembre de 1546, le mencionan como letrado de este cabildo, invocando sus saberes en cuanto a las tierras, p. 157, op. cit.

John Rowe me dijo que tenía una copia del MS de Morua encontrado en Londres por uno de los estudiantes de Ballesteros. Zuidema también lo vio. Parece ser otro documento bastante diferente del que publicó Bayle.

1 Traducida del francés. 
Pues bien, querido colega, ya está iniciada nuestra correspondencia. Supongo que ya recibió los artículos que le envié; cualquier comentario será bienvenido.

Reciba, Ud. y sus colegas, las felicitaciones que merecen las nuevas Etudes.

John V. Murra

\section{III) A propósito de Polo, Cobo y Román}

(a) Murra escribe: "[John Rowe] presenta a Cobo como la mejor fuente y cita un ejemplo de ello, pp. 265-66" del Handbook. Este ejemplo se refiere al sistema de partición de las tierras. Efectivamente, Rowe escribe, p. 265: "The cultivation of the reserved fields has been well described by father Bernabé Cobo, the greatest man who has ever written about Inca customs (writing about 1653)", antes de citar un muy largo extracto de la Historia del Nuevo Mundo (XII, xxviii), traducido al inglés, de este autor. Rowe no había advertido que, según lo revela Murra, el texto de Cobo no hace más que reproducir otro debido a Polo. Además de lo dicho por Murra, al cotejar los dos textos que este señala, pude constatar que Cobo -quien escribía en 1650- se atribuye tranquilamente la encuesta efectuada y mencionada en 1571 por Polo. En efecto, leemos en el texto Polo: "e yo me he hallado presente a la división [de las tierras] en munchas [partes del rreyno], e prinçipalmente en la provincia de Chucuyto" (1916:70), la transcripción de Cobo siendo la siguiente: "Y este modo de partición [de las tierras] se guarda hoy en las provincias del Collao y en otras partes y yo me he hallado presente al hacerla en la provincia de Chucuito" (B.A.E. 91, Atlas, Madrid 1956:121b). A propósito del Handbook, t. II, recordaré que contiene también un estudio de John Murra, titulado: "The Historic Tribes of Ecuador".

(b) En el caso de Morúa, lo que apunta Murra es también exacto y significativo. El texto señalado de Román y Zamora concierne los ganados del Sol y la protección de los delincuentes por la Iglesia. Es exactamente conforme a su modelo, salvo un detalle: mientras Román escribe "los del rreino de Nueva España y los del Perú" (p. 122) Morúa cambia por: "los deste Reino" (p. 335), y al conservar "no lo sé, ni lo he podido descubrir" (p. 136) se apropia la autoría. Esto nos muestra que Cobo, al practicar el mismo método de apropiación, como hemos visto, se ceñía a una vieja costumbre del plagio. En cuanto a Román, es también exacto que fue gran copiador, hasta sacar lo principal de su texto de la Apológica historia sumaria de Las Casas, según ya lo había señalado Marcel Bataillon, a principios de los años de 1950.

Es relevante el papel del análisis comparativo de fuentes en las investigaciones antropológicas de Murra.

(c) El pasaje del documento de la Revista del archivo histórico del Cuzco referente a la estadía de Polo en el Cuzco ya en 1546, es el siguiente, p. 144: “...de lo cual en nuestro Libro de Cabildo firmamos nuestros nombres; que fue hecha y otorgada en la dicha ciudad del Cuzco, a diez y siete días del mes de agosto, año del nascimiento de Nuestro Salvador Jesucripsto de mill y quinientos e quarenta e seis años, siendo presentes por testigos: el Licenciado Alonso Péres Martel, e Sebastian de Cota, el Licenciado Polo, estantes en la dicha ciudad y los dichos señores lo firmaron de su nombre...".

\section{IV) Inicio de una relación universitaria. Algunos recuerdos de otros tiempos}

Un día en París, mientras le iba acompañando desde el Museo del Hombre, donde acababa de dictar una conferencia, hasta su despacho de la UNESCO, Alfred Métraux me habló de los trabajos importantes y novedosos de John Murra sobre la economía del Estado inca. Mucho más tarde me enteré de que Métraux y Murra se habían conocido ya en Washington en 1943 (1). Este fue el punto de partida que me permitió luego enviarle a John el primer número de la revista en cuya gestación yo me había ocupado, inmediatamente después de llegar a la Universidad de Aix-en-Provence. En esta revista ${ }^{2}$ un artículo mío se esforzaba en mostrar que el cronista Morúa, según la Historia del origen y genealogía real de los Reyes del Perú (publicada por Constantino Bayle, S.J. en 1946), había copiado íntegramente muchos pasajes del Confessionario para curas de indios, Lima 1585, en particular trozos del resumen del Tratado y averiguación..., de Polo de Ondegardo, contenido en esta obra.

En la carta aquí reproducida, John Murra reivindica la importancia de los escritos de Polo, que fue el nexo de esta primera correspondencia; revela datos precisos y preciosos sobre él y también sobre los cronistas Murúa, Cobo y Román y Zamora. Esto va junto con noticias valiosas sobre circunstancias que en aquel entonces eran de mucho interés, como 
las referencias a la existencia de una nueva tesis sobre el sistema de ceques del Cuzco "de gran importancia" y al descubrimiento, casualmente, de un nuevo manuscrito de Murúa. Con aquella carta se hacía patente que John, manifestando confianza y franqueza, transmitía generosamente a un joven colega andinófilo desconocido algunos datos útiles sacados de sus investigaciones personales, no publicados y por lo tanto confidenciales. Al mismo tiempo, desechando cualquier lisonja de cumplido, no vacilaba en criticar lo que era legítimo criticar, esto es, mi error en cuanto a la fecha de la llegada de Polo al Cusco. Por todo esto, creo que se puede decir que esta primera carta es notable por el contenido tanto científico como humano.

Conocí a John personalmente por primera vez en mayo de 1965, en el Perú, donde permanecí de investigador del Instituto Francés de Estudios Andinos durante dos años. John tenía un apartamento en el centro moderno de Lima e iba preparando la edición de la Visita de Huánuco de Diez de San Miguel. Era la época en que comentaba y difundía la temática de "la verticalidad" y de "los pisos ecológicos", abogando por la importancia de las visitas administrativas del siglo XVI, y después por 'la reciprocidad'. Dictaba clases en el Instituto de Etnología de San Marcos, que dirigían los doctores Luis E. Valcárcel y José Matos Mar. Fundó con ellos y otras personas el Instituto de Estudios Peruanos.

La brillante capacidad intelectual y el excepcional don de gentes de John, a lo que conviene añadir el fino humorismo, todo ello nutrido por su verdadera vocación apostólica y misionera laica proandina, por la poderosa ideología científica que había constituido, por su rebosante dinamismo, junto con su mucha autoridad -y a veces también autoritarismo- le permitieron seducir intelectualmente y establecer privilegiados contactos científicos tanto locales como lejanos. Aportaba nuevos métodos de investigación en el dominio de la antropología histórica y económica y los comunicaba con pericia y entusiasmo, llegando a formar grupos de excelentes y fieles discípulos. Siempre servicial, ayudaba a concretizar las aptitudes de cada uno de ellos, que había sabido descubrir. Es indudable que entonces contribuyó eficazmente a la renovación y desarrollo de los estudios andinos. También promovía, organizaba y controlaba trabajos de campo e invitaba a varios de nosotros, aunque no especialistas, a visitarlos. Algo más, patente e importante señala el Dr. Carlos Contreras justamente: "con los hombres andinos... nos enseñó a tener un diálogo respetuoso y entre iguales".

Una vez, con otros colegas, me llevó a Huánuco, donde tenía a su cargo el control de varias investigaciones y entre ellas algunas en Huánuco Viejo; en la Universidad estaba de Decano Edmundo Guillén. A esta Universidad llevó la primera fotocopiadora, según recuerda el mismo Dr. Carlos Contreras. En ella nos hicieron "Doctores honoris causa...

Leíamos afanosamente sus trabajos. Su tesis inédita se conocía por fotocopias. Nombrado titular de las conferencias Lewis Morgan por el año de 1969, había tomado esta resolución: "decidí que las cuatro conferencias formarán un libro más bien pequeño, de carácter más comparatista, para el público de Estados Unidos, donde de todos modos conocen mi tesis. Se llamará Reciprocity and distribution in Andean Civilisations. Al mismo tiempo pienso en hacer otro libro, más grueso y detallado que se llamará The Economic Organization of Tawantinsuyu y que se traducirá al español para el público que no ha leído mi tesis y que podrá disponer así de toda la documentación... Este no será necesario publicarlo en inglés" (Cornell, 18-01-1969).

Años después, participamos en México, durante tres semanas, en un congreso dedicado a estudios comparativos Andes-Mesoamérica, que John había contribuido en gran parte a organizar con Arturo Warman y Angel Palerm, su viejo y gran amigo del tiempo de la guerra en España. Los más próximos al Maestro estábamos alojados con él en las ruinas de Teotihuacán en unas casas habitualmente reservadas a los arqueólogos. Chile era representado por Jorge Hidalgo y Agustín Llagostera?. Las sesiones del congreso eran en la Universidad Ibero-Americana; para ir y regresar había que cruzar con autobús toda la ciudad de México por la mañana y, de regreso por la tarde; en cada viaje de ida y vuelta tardábamos más de hora y media. Un día, John decidió alquilar un carro, aunque no manejaba. Por varios días tuve el honor de servirle de chofer.

Afectaba, como bromeando, no interesarse por las llamadas cuestiones religiosas (a las que yo dedicaba mis actividades) invocando desagradables recuerdos de juventud a propósito de los "especialistas religiosos", cuando joven en Rumania, país donde vivía su hermana, "física jubilada, más joven que yo" y su gran amiga Beatriz Iosifescu. Yo me dedicaba al estudio de la llamada "extirpación de la idolatría”, y empezaba una carta llamándome chistosamente 'su extirpador favorito' (Cornell, 
18-01-1969). Sin embargo estuvo atento a mi trabajo. No escatimaba comunicarme eventuales informes o consejos en este campo. Me ayudó a encontrar la palabra conveniente ("lutte") en el título de mi libro sobre el tema, y quería anunciar su salida en Nispa Ninku, revista que proyectaba publicar. En realidad también trataba de religión andina en sus clases. Invitado por él, en Cornell yo había dictado una conferencia sobre la Instrucción para descubrir todas la huacas del Pirú con sus camayos y haciendas, de Cristóbal de Albornoz. $\mathrm{Al}$ año siguiente me escribía: "En otoño dicté aquí mi primera clase sobre los Andes y un día los estudiantes leyeron las instrucciones de Albornoz, publicadas por Ud. ¡Ay! el español de aquella época los hace testarudos; teóricamente nadie puede presenciar esta clase si no sabe español y la mayoría lo hablan... pero leer al buen padre Cristóbal, esto es otro asunto..." (Cornell, 16-01-1969). Cuando publiqué Cultura Andina y Represión, declaró en un aviso, que se publicó, que las visitas y los procesos de idolatrías de Cajatambo eran tan importantes para el conocimiento de la cultura autóctona como la relación quechua de Huarochirí.

Apelaba con frecuencia a la necesidad de buscar y publicar nuevas fuentes sobre el antiguo Perú. Había instado a José María Arguedas a que tradujera de nuevo la famosa y ya citada relación de Huarochirí, aunque él mismo no trabajó en el estudio etnográfico que en un principio había previsto hacer. En carta del 26-03-1970, escribe que su estudiante y amiga Freda "trabaja ahora a averiguar detalles en el MS de Huarochirí, porque estamos haciendo aquí una nueva traducción. Yo había enviado a JM [José María Arguedas] un capítulo recién traducido por Jorge Urioste, de Sucre, que preparará su doctorado aquí con un análisis lingüístico del texto y una nueva traducción. A JM le agradó ver esta nueva traducción, que será más etnológica y lingüística...".

Poco tiempo después de la muerte de Arguedas, en carta del 26-03-1970, desde Cornell, me decía: "Su carta, después del coloquio de París, me llegó sin demora, pero la del 6 de enero, con los renglones de despedida de JM solamente la recibí ayer [...]. No hay duda, su muerte nos deja huérfanos, como reza el cliché. De verdad, solo él entendía la importancia del material andino y la realidad aparte de aquella cultura. Aunque hallemos jóvenes que conozcan las lenguas andinas, nosotros somos quienes los hallaremos y en sus vidas ya será tarde (tendrán por lo menos 20 años...); serán filtrados por escuelas aculturantes y animados por visiones 'modernizantes'. El proceso para descubrir lo que han heredado tardará mucho y sin duda quedaremos desilusionados. No recibí cartas de Lima. Las dos últimas datan de principios de septiembre. En las dos habla, como a Ud. ${ }^{3}$, de la novela. Entre otras cosas, dice: "todo iba bien hasta hace dos meses. Pero Sybila no quiso venir a Santiago por quince días sin dar razón alguna y eso me causó un trastorno increíble. Me voy dentro de cuatro días a Lima. La novela ha quedado inconclusa pero no trunca. Podrá ser publicada así como está y creo que será un buen documento sobre el Perú. No sé qué haré ni cómo a mi vuelta a Lima. Vuelvo algo peor de como vine pero con un libro en las manos..." Y después : "Te escribiré desde Lima. Voy excitado, oliendo un poco la resurrección y la muerte, por una y otra oreja".

Al terminar esta carta, John expresaba su sensibilidad ante la naturaleza con tono poético, en un pasaje que dejaré en francés, sin traducirlo: "Le printemps est presque là. Ce matin les oies sauvages passaient par milliers par dessus de ma tête ñelles trompettent et cíest beau de les écouterLe printemps níest pas loin, malgré les neiges de la dernière fin de semaine..."

Estas son algunas miajas de recuerdos relativos al grande e inolvidable John Murra ${ }^{4}$.

Por fin, en parte influenciado por John, seguí estudiando a Polo de Ondegardo y juntando datos. En 1990 inicié un proyecto colectivo de búsqueda, reexamen y edición de sus escritos con el Dr. Fermín del Pino, del Centro Superior de Investigaciones Científicas de Madrid; proyecto que ahora él va conduciendo. Se anuncia una próxima publicación de textos importantes. 


\section{Notas}

$1 \quad C f$. An interview with John V. Murra. Introduction by John Howland Rowe. Hispanic American Historical Review 64 (4), 1984:640.

2 Este número contiene los artículos siguientes: S. Zavala ("Un aspecto del pensamiento de Bartolomé de las Casas"), P. Guiral ("Bolivar ou l'isolement dans l'histoire"), J. Durand ("El proceso de redacción de las obras del Inca Garcilaso"), P. Duviols ("Les sources religieuses du chroniqueur péruvien Fray Martín de Murúa”), G. A. de
Reparaz ("Un exemple de géographie appliquée au Pérou: le recensement de Chosica").

3 Alude a la carta de despedida de José María Arguedas a Pierre Duviols, con fecha del 21 de noviembre de 1969, publicada en la revista Runa, Nº, noviembre-diciembre 1977, Lima, p. 18. Yo había comunicado esta carta a John.

4 Todos los extractos de las cartas citadas en español son traducidos del francés, excepto el extracto de la carta de J. M. Arguedas, que es copia del original. 
